\title{
Relationship of attention-deficit/hyperactivity disorder symptom severity with severity of alcohol-related problems in a sample of inpatients with alcohol use disorder
}

\author{
This article was published in the following Dove Press journal: \\ Neuropsychiatric Disease and Treatment \\ 7 July 2016 \\ Number of times this article has been viewed
}

\section{Muge Bozkurt ${ }^{1}$ \\ Cuneyt Evren' \\ Gokhan Umut' \\ Bilge Evren²}

'Research, Treatment and Training Center for Alcohol and Substance Dependence, Bakirkoy Prof Dr Mazhar Osman Training and Research Hospital for Psychiatry, Neurology and Neurosurgery, ${ }^{2}$ Department of Psychiatry, Baltalimani State Hospital for Muskuloskeletal Disorders, Istanbul, Turkey
Correspondence: Muge Bozkurt Bakirkoy Prof Dr Mazhar Osman Training and Research Hospital for Psychiatry,

Neurology and Neurosurgery,

Zuhratbaba, Tevfik Saglam Street,

No 25/2 Bakirkoy, Istanbul, 34I47, Turkey

Tel +90212409 I5 I5

Fax +90 2I2 409 I590

Email mugeulku@gmail.com
Purpose: Attention-deficit/hyperactivity disorder (ADHD) has been shown to be related to a higher risk of developing psychiatric problems such as depressive disorders, substance use disorder, and impulsivity. Adults who have comorbid ADHD and alcohol use disorder (AUD) are at greater risk of negative outcomes. Thus, it is important to evaluate the relationship of ADHD symptoms and the severity of alcohol-related problems among patients with AUD. The aim of the present study was to evaluate the effect of ADHD symptoms on severity of alcoholrelated problems, while controlling the effects of depression and impulsivity in a sample of inpatients with AUD.

Patients and methods: Participants $(n=190)$ were evaluated with the Beck Depression Inventory, the Short Form Barratt Impulsiveness Scale, the Michigan Alcohol Screening Test, and the Adult ADHD Self-Report Scale.

Results: Severity of the scale scores was positively correlated with each other. Although severity of depression and impulsivity (particularly non-planning impulsivity) predicted the severity of alcohol-related problems in a linear regression model, when severity of ADHD symptoms was included in the analysis, the inattentive subscale score, in particular, predicted the severity of alcohol-related problems together with non-planning impulsivity, whereas depression was no longer a predictor.

Conclusion: These findings suggest that, together with non-planning impulsivity, symptoms of ADHD (particularly inattentive factor) are an important factor that predict alcohol-related problems, while controlling the severity of depressive symptoms among inpatients with AUD. Keywords: ADHD, alcohol-related problems, alcohol use disorder, depression, impulsivity

\section{Introduction}

Attention-deficit/hyperactivity disorder (ADHD) is a childhood-onset disorder that persists into adolescence and adulthood in more than half of the cases ${ }^{1}$ and is characterized by hyperactivity/impulsivity (HI) and inattention (IN) that negatively impacts one's ability to function and fulfill social and personal obligations. ${ }^{2}$ Studies of adults with substance use disorder (SUD) find that the prevalence for possible ADHD, according to screening test results, is between $21 \%$ and $23.1 \% .^{3-6}$ An international multicenter study in ten countries, among treatment-seeking patients with SUD, reported that the prevalence of ADHD among inpatients with alcohol use disorder (AUD) ranged between 5\% (Hungary) and 22\% (Norway); and among outpatients with AUD ranged between 4\% (Spain) and 14\% (Norway). ${ }^{7}$ Despite this high comorbidity, ADHD may be 
underdiagnosed in the SUD population. It was reported that the prevalence of undiagnosed ADHD within SUD inpatients was approximately $12 \%{ }^{8}$

Impulsivity, defined as a tendency toward rash action, ${ }^{9}$ is a core component of the ADHD phenotype as well as a correlate of alcohol use. ${ }^{10}$ This trait overlap supports arguments that impulsivity explains the heightened rates of alcohol abuse in individuals with ADHD. ${ }^{11}$

In addition to SUD and impulsivity, ADHD has been shown to be related to a higher risk of psychiatric problems such as depressive disorders. ${ }^{12}$ A history of ADHD in adolescence was associated with an elevated risk of depression through early adulthood and this relationship remained significant after controlling for psychosocial impairment and co-occurring psychiatric disorders. ${ }^{13}$ In a study conducted among treatment-seeking patients with SUD in ten European countries, major depression in patients with alcohol as primary substance of abuse (odds ratio $=4.1,95 \%$ confidence interval $=2.1-7.8$ ) is prevalent in patients with ADHD compared to patients without ADHD. ${ }^{6}$ Additionally, significant associations were found between ADHD symptom severity and self-reported histories of self-harm behavior, suicidal ideation, and suicide attempts, which are mediated by psychosocial variables including AUD comorbidity. ${ }^{14}$

Individuals with SUD and ADHD had significantly higher self-rated impairments across several domains of daily life; suicide attempts, and depression recorded in their case records, ${ }^{15}$ which make these related factors highly relevant for clinical practice. Because adults who have comorbid ADHD and AUD are at greater risk for negative outcomes, ${ }^{16}$ they may be more difficult to treat than adults with only one of the diagnoses. Thus, it is important to evaluate the relationship of ADHD symptoms and alcohol-related problems among patients with AUD. Another area of interest is the notion that impulsivity and/or depression (variables commonly seen with both ADHD and AUD), rather than ADHD, explains the negative alcohol-related problems in adulthood.

The present study hypothesizes that there is a relationship between the severity of ADHD symptoms and alcohol-related problems among male inpatients with AUD, even after controlling the possible influence of depressive symptoms and severity of impulsivity. To our knowledge, this is the first study to evaluate the relationship between alcohol-related problems and ADHD symptoms among male subjects with AUD, which is an important phenomenon in clinical settings. Conducted in Turkey, this study provides knowledge in a cross-cultural context as well.

\section{Patients and methods}

\section{Subjects}

The study was conducted in Bakirkoy Training and Research Hospital for Psychiatry, Neurology and Neurosurgery, Alcohol and Drug Research, Treatment and Training Center in Istanbul between August 2014 and June 2015. It is a specialized center for SUD with 84 inpatient beds (36 beds for AUD) and accepts patients from all over Turkey. Patients' written informed consent was obtained after the study protocol was thoroughly explained. As no invasive approach was performed in the present study and it is not a drug research, ethical approval was not required by the Insitutional Review Board of Bakirkoy Prof. Dr. Mazhar OsmanTraining and Research Hospital for Psychiatry, Neurology and Neurosurgery.

Exclusion criteria were illiteracy, mental retardation or cognitive impairment, and comorbid psychotic disorder according to clinical interview, whereas having a personality disorder was not an exclusion criterion. Two patients were excluded due to illiteracy and one patient due to cognitive deficits. Although none of the patients refused to participate in the study, 21 patients were excluded because they left some parts of the scales uncompleted, did not give the forms back or left the treatment program prematurely, that is, before filling in the forms. Thus, a total of 190 consecutively admitted male alcohol-dependent inpatients were considered for participation in the study.

The sample included only males because during the study period only five female patients with AUD were admitted to the clinic and we decided to exclude these patients as it may cause bias. All participants met the Diagnostic and Statistical Manual of Mental Disorders, Fifth Edition diagnostic criteria for AUD according to the psychiatric interview conducted by an expert clinician. AUD was the only diagnosis that was made according to the clinical interview. Interviews with the study group were conducted after a detoxification period, that is, 3-4 weeks after the last day of alcohol use. For most of the participants, the last day of alcohol use was the day before admission, whereas approximately one fifth quit drinking with the help of outpatient treatment, but wanted to receive inpatient treatment anyway. If benzodiazepine was ever used for withdrawal symptoms during this period, the interview was conducted after stopping benzodiazepine. Main pharmacotherapies that were used during the interview were vitamin complexes containing thiamine and acamprosate for craving.

\section{Measures}

The scales used in the present study were chosen because they were all well-known self-rating measures in the literature, validated in Turkish, and frequently used in patients with AUD. 


\section{Beck Depression Inventory}

Symptoms and severity of depression were evaluated by using the Beck Depression Inventory, ${ }^{17}$ Turkish version. ${ }^{18}$

\section{Short Form Barratt Impulsiveness Scale}

The latest form of Short Form Barratt Impulsiveness Scale (BIS-11-SF) was developed in 1995, which was a 30-item scale. ${ }^{19}$ A reliability and validity study for the Turkish version of this scale was conducted by Gulec et al. ${ }^{20} \mathrm{~A} 15$-item short form of the BIS (BIS-11-SF) that retains the three-factor structure (non-planning impulsivity, motor impulsivity, and attention impulsivity), and maintained good reliability and validity was presented by Spinella, ${ }^{21}$ whereas an adaptation study of the Turkish version of this scale was conducted by Tamam et al..$^{22}$

\section{Michigan Alcohol Screening Test}

The severity of dependence was assessed with the Michigan Alcohol Screening Test (MAST), which was developed as "rapid and effective screening for lifetime alcohol-related problems and alcoholism" for a variety of populations. ${ }^{23}$ Its focus on drinking behavior and adverse consequences makes it a widely used measure for examining significant problems associated with alcohol use in medical, legal, and interpersonal areas of life. It consists of 25 brief true/ false items that are self-administered in approximately 10 minutes. Scoring is accomplished after reverse scoring four of the 25 items and assigning weighted scores. These weighted scores are then summed; the sum represents a total score reflecting severity of alcohol-related problems. The Turkish version of the MAST is valid and reliable for screening severity of dependence in both alcohol- and drugdependent patients. ${ }^{24}$

\section{Adult ADHD Self-Report Scale}

In conjunction with the World Health Organization (WHO) Kessler et $\mathrm{al}^{25}$ developed a self-report scale for the screening of ADHD in adults (Adult ADHD Self-Report Scale [ASRS]-v1.1; 10). The scale they propose is a short, 18-item scale (nine items for IN and nine items for HI) which relates directly to the Diagnostic and Statistical Manual of Mental Disorders, Fourth Edition, text revision, diagnostic criteria. These 18 statements describe aspects of ADHD that are rated on a five-point Likert scale from " 0 - never" to " 4 - very often". The ASRS is a widely used and validated instrument, the six-item screening version has been shown to outperform the full 18 -item version in sensitivity (68.7\% vs $56.3 \%)$ and specificity $(99.5 \%$ vs 98.3\%) in an American general population. ${ }^{25,26}$ The Turkish version of the scale was previously validated on a sample of university students. ${ }^{27}$ Specifically, in a sample of patients with AUD, psychometric characteristics of the Turkish version were analyzed by Evren et $a 1,{ }^{28}$ and satisfactory properties were found. In the present study, the 18-item version was used in order to evaluate the severity of IN and HI symptoms. The severity of these dimensions was measured by summing the scores of each of the nine items per subscale. ASRS-18 evaluates the symptoms of ADHD over the past 6 months. Nevertheless, the result of the test does not replace a clinical diagnosis and the clinician must take false positives into consideration by evaluating ASRS positives with gold standard scales.

\section{Statistics}

Descriptive statistics were computed as mean \pm standard deviation, count, and percent frequency in Table 1. Correlation analyses (Pearson, bivariate) between MAST, ASRS, BIS-11-SF, and depression scores were performed. In the hierarchical linear regression models for alcohol-related problems, depression score was entered as independent variable in the first step (Enter), whereas in the second "A" step the BIS-11-SF and in the second "B" step dimensions (nonplanning, motor, and attentive) of BIS-11-SF (Stepwise) were entered as independent variables. In the third " $A$ " step total ASRS score and in the third "B" step (Stepwise) IN

Table I Sociodemographic variables and severity of clinical variables

\begin{tabular}{lll}
\hline Variables & Mean (n) & SD (\%) \\
\hline Age & 44.69 & 10.19 \\
Duration of education & 9.25 & 3.65 \\
Marital status & & \\
$\quad$ Married & 116 & 61.1 \\
$\quad$ Single & 40 & 21.1 \\
$\quad$ Divorced/widower & 34 & 17.9 \\
Employment & & \\
$\quad$ No & 55 & 28.9 \\
Yes & 65 & 34.2 \\
Part-time & 26 & 13.7 \\
$\quad$ Retired & 44 & 23.2 \\
Michigan Alcohol Screening Test & 27.63 & 10.20 \\
Beck Depression Inventory & 16.66 & 11.46 \\
BIS-II-SF & 30.91 & 6.33 \\
$\quad$ Non-planning & 11.17 & 3.18 \\
Motor & 10.44 & 2.62 \\
$\quad$ Attentional & 9.30 & 2.43 \\
ASRS & 25.77 & 10.94 \\
Inattentive & 12.12 & 6.18 \\
Hyperactive/impulsive & 13.64 & 6.16 \\
\hline
\end{tabular}

Abbreviations: BIS-II-SF, Short Form Barratt Impulsiveness Scale; ASRS, Adult ADHD Self-Report Scale; SD, standard deviation; ADHD, attention-deficit/ hyperactivity disorder. 
Table 2 Correlations between the scale scores $(P<0.00 \mathrm{I})$

\begin{tabular}{|c|c|c|c|c|c|c|c|c|}
\hline Scales & BDI & NPI & MI & Al & BIS-I I-SF & IN & HI & ASRS \\
\hline MAST & 0.353 & 0.360 & 0.259 & 0.309 & 0.407 & $0.48 I$ & $0.25 I$ & $0.4 \mid 4$ \\
\hline BDI & & 0.425 & 0.463 & 0.453 & 0.579 & 0.564 & 0.416 & 0.553 \\
\hline NPI & & & 0.278 & 0.421 & 0.779 & 0.390 & 0.333 & 0.408 \\
\hline MI & & & & 0.474 & 0.736 & 0.288 & $0.44 I$ & 0.412 \\
\hline Al & & & & & 0.792 & 0.434 & 0.297 & 0.413 \\
\hline BIS-I I-SF & & & & & & 0.482 & 0.464 & 0.534 \\
\hline
\end{tabular}

Abbreviations: MAST, Michigan Alcohol Screening Test; BDI, Beck Depression Inventory; NPI, non-planning impulsivity; MI, motor impulsivity; Al, attention impulsivity; BIS-I I-SF, Short Form Barratt Impulsiveness Scale; IN, inattention; HI, hyperactivity/impulsivity; ASRS, Adult ADHD Self-Report Scale; ADHD, attention-deficit/hyperactivity disorder.

and HI dimensions of ASRS were entered as independent variables. For all statistical analyses, the level of significance was set at $P=0.05$.

\section{Results}

Sociodemographic variables and the severity of clinical variables are shown in Table 1. We showed four main sociodemographic variables and means of the scales that were used in the present study to give an idea of the sample. Severity of scale scores was positively correlated with each other (Table 2). Although severity of depression and impulsivity (particularly non-planning impulsivity) predicted the severity of alcohol-related problems in a linear regression model, when severity of ADHD symptoms was included in the ADHD symptom analysis, particularly the IN subscale score predicted the severity of alcohol-related problems together with non-planning, whereas depression was no longer a predictor (Table 3).

\section{Discussion}

The main finding of this present study was that the severity of ADHD symptoms, particularly IN dimension, together with severity of impulsivity, particularly non-planning impulsivity, predicted the severity of alcohol-related problems. This finding may suggest that although HI may be more strongly related with early onset of alcohol use or AUD, ${ }^{29,30}$ together with non-planning impulsivity as independent construct, severity of the IN dimension of ADHD is more strongly associated with the severity of alcoholrelated problems.

While "impulsivity" may be defined as a part of the ADHD construct, the term may also be applied to characteristics that are conceptually and psychometrically distinct. The BIS-11-SF measures three subtypes of impulsiveness: cognitive (attentional) impulsiveness (IN and cognitive instability), motor impulsiveness (motor disinhibition), and nonplanning impulsiveness (lack of self-control and intolerance

Table 3 Predictors of severity of alcohol-related problems measured with the Michigan Alcohol Screening Test (MAST)

\begin{tabular}{|c|c|c|c|c|c|}
\hline \multirow[t]{2}{*}{ Model } & \multicolumn{2}{|c|}{ Unstandardized coefficients } & \multirow{2}{*}{$\frac{\text { Standardized coefficients }}{\text { Beta }}$} & \multirow[t]{2}{*}{$t$} & \multirow[t]{2}{*}{$P$-value } \\
\hline & B & Standard error & & & \\
\hline \multicolumn{6}{|l|}{ Step I } \\
\hline BDI & 0.314 & 0.061 & 0.353 & 5.174 & $<0.001$ \\
\hline \multicolumn{6}{|l|}{ Step $2^{\mathrm{a}}$} \\
\hline $\mathrm{BDI}$ & 0.157 & 0.072 & 0.177 & 2.185 & 0.030 \\
\hline BIS-II-SF & 0.491 & 0.130 & 0.304 & 3.762 & $<0.001$ \\
\hline \multicolumn{6}{|l|}{ Step $2^{\mathrm{b}}$} \\
\hline BDI & 0.217 & 0.065 & 0.244 & 3.334 & 0.001 \\
\hline Non-planning & 0.823 & 0.235 & 0.256 & 3.503 & 0.001 \\
\hline \multicolumn{6}{|l|}{ Step $3^{\mathrm{a}}$} \\
\hline BDI & 0.108 & 0.07 I & 0.122 & 1.513 & 0.132 \\
\hline Non-planning & 0.644 & 0.235 & 0.201 & 2.739 & 0.007 \\
\hline ASRS & 0.247 & 0.074 & 0.265 & 3.325 & 0.001 \\
\hline \multicolumn{6}{|l|}{ Step $3^{b}$} \\
\hline $\mathrm{BDI}$ & 0.056 & 0.070 & 0.063 & 0.801 & 0.424 \\
\hline Non-planning & 0.604 & 0.227 & 0.188 & 2.662 & 0.008 \\
\hline ASRS-inattentive & 0.614 & 0.128 & 0.372 & 4.807 & $<0.001$ \\
\hline
\end{tabular}

Notes: Step I: $F=26.77, d f=I, 188, P<0.001$, adjusted $R^{2}=0.120$, step $2^{a}=F=21.40, d f=2,187, P<0.001$, adjusted $R^{2}=0.178, R^{2}$ change $=0.062$, step $2^{b}=F=20.32, d f=2,187$, $P<0.00 \mathrm{I}$, adjusted $R^{2}=0.170, R^{2}$ change $=0.054$, step $3^{\mathrm{a}}=\mathrm{F}=17.96, \mathrm{df}=3,186, P<0.00 \mathrm{I}$, adjusted $R^{2}=0.212, R^{2}$ change $=0.046$, step $3^{\mathrm{b}}=\mathrm{F}=22.85, \mathrm{df}=3, \mathrm{I} 86, P<0.00 \mathrm{I}$, adjusted $R^{2}=0.258, R^{2}$ change $=0.091$.

Abbreviations: BDI, Beck Depression Inventory; ASRS, Adult ADHD Self-Report Scale; ADHD, attention-deficit/hyperactivity disorder; df, degrees of freedom; BIS-I I-SF, Short Form Barratt Impulsiveness Scale. 
of cognitive complexity). ${ }^{19}$ Thus, although impulsivity subdimensions measured with BIS-11-SF may overlap with ADHD symptoms, ${ }^{11}$ they are different constructs. Impulsivity and consequent risk-taking are associated with both ADHD and AUD. Impulsivity is a core diagnostic feature of $\mathrm{HI}$ and combined presentations of ADHD, and may be a determining factor in the initiation and maintenance of alcohol use, $, 90,31$ with increased levels of impulsivity consistently found among those with AUD. ${ }^{10,32}$ Additionally, alcohol consumption may cause disinhibition among adults with ADHD. ${ }^{33}$

A cross-sectional study that investigated associations of lifetime ADHD symptom levels with individual classes of lifetime substance dependence in a population-based sample of 34,653 American adults reported that both HI and IN were uniquely associated with alcohol, nicotine, and polysubstance dependence, but only $\mathrm{HI}$ was uniquely associated with illicit substance dependence. ${ }^{29}$ Data obtained from the National Epidemiologic Survey of Alcohol and Related Conditions ( $\mathrm{n}=33,588)$, which was conducted in the USA, showed that ADHD subtypes (IA, HI, and combined) are consistently associated with substance use and SUD. The relatively stronger association of HI symptoms with substance use and abuse/dependence was consistent with the current literature noting impulsivity as a precursor of substance use and SUD. ${ }^{30}$ Thus, finding that the IN dimension, but not the HI dimension, predicted the severity of alcohol-related problems in the present study may suggest that while $\mathrm{HI}$ is clearly and more strongly implicated in the path from early alcohol use to AUD, ${ }^{29,30} \mathrm{IN}$, which increases with age, ${ }^{34}$ may be associated with the severity of alcohol-related problems in adulthood. These findings are broadly consistent with models suggesting that $\mathrm{HI}$ is associated with greater impairment in childhood, whereas IN is emerging as a more salient predictor of outcomes later in development. ${ }^{16,35}$ Elevations of HI may be more strongly associated with initiation/early use of alcohol, whereas IN in adulthood may be a greater liability once AUD is established. ${ }^{36}$

A study conducted in Turkish adolescents showed that the severity of ADHD symptoms was correlated with the severity of depression. ${ }^{37}$ Also in this study, among substance clusters (alcohol, any drugs, and tobacco) investigated, only lifetime use of alcohol predicted the severity of ADHD symptoms. ${ }^{37}$ Independent or substance-induced depression is a common phenomenon in patients with AUD. ${ }^{38}$ In our previous study, the severity of depressive symptoms among detoxified Turkish male alcohol-dependent inpatients was associated with higher severity of alcohol-related problems. ${ }^{39}$ Although severity of depressive symptoms was associated with the severity of alcohol-related problems in the present study, it was no longer a predictor when ADHD symptom severity was entered in the regression analysis as an independent variable, which may suggest that depressive symptoms in these patients are related with the IN symptoms and consequences of these symptoms. Consistent with this, adults with ADHD report high levels of stress in everyday life and poor coping ability, ${ }^{40}$ and AUD may even be a destructive coping strategy in this population.

\section{Limitations}

The present study also has some limitations. First, because this study is cross-sectional, its findings cannot indicate the causal relationships among the primary constructs of interest. Second, female patients may have a different profile concerning ADHD, impulsivity, depression, and alcohol-related problems. Third, actually we evaluated ADHD symptoms rather than diagnosis of $\mathrm{ADHD}$, and it is suggested that the severity of ADHD symptoms may change according to the sample, the scale that is used to measure ADHD symptoms, and design of the study. ${ }^{7}$ Fourth, although all the scales used in the present study were validated in Turkish, since they are self-rating screening scales, they may only indicate the individuals with a high risk of ADHD or depression, rather than the diagnosis. Related to this, although cognitive impairment was one of the exclusion criteria in the present study and interviews were conducted 3-4 weeks after the last day of alcohol use, overlapping symptoms between alcohol withdrawal and ADHD may still have led to higher scores in the ASRS. Finally, the generalizability of the findings of the present study to the wider, non-treatment-seeking, mixed-sex population with AUD requires further study.

\section{Conclusion}

These findings suggest that to better understand alcoholrelated problems among inpatients with AUD, clinicians must carefully evaluate ADHD symptoms, particularly the inattentive component, and impulsivity, particularly the nonplanning component among this population.

\section{Disclosure}

The authors report no conflicts of interest in this work.

\section{References}

1. Klein RG, Mannuzza S, Olazagasti MA, et al. Clinical and functional outcome of childhood attention-deficit/hyperactivity disorder 33 years later. Arch Gen Psychiatry. 2012;69(12):1295-1303.

2. Ivanov I, Yehuda R. Optimizing fitness for duty and post-combat clinical services for military personnel and combat veterans with ADHD-a systematic review of the current literature. Eur J Psychotraumatol. $2014 ; 5$. 
3. Johann M, Bobbe G, Putzhammer A, Wodarz N. Comorbidity of alcohol dependence with attention-deficit hyperactivity disorder: differences in phenotype with increased severity of the substance disorder, but not in genotype (serotonin transporter and 5-hydroxytryptamine-2c receptor). Alcohol Clin Exp Res. 2003;27(10):1527-1534.

4. Ohlmeier MD, Peters K, Wildt BT, et al. Comorbidity of alcohol and substance dependence with attention-deficit/hyperactivity disorder (ADHD). Alcohol Alcohol. 2008;43(3):300-304.

5. Roncero C, Ortega L, Pérez-Pazos J, et al. Psychiatric comorbidity in treatment-seeking alcohol dependence patients with and without ADHD. J Atten Disord. Epub 2015 Aug 12.

6. van Emmerik-van Oortmerssen K, van de Glind G, van den Brink W, et al. Prevalence of attention-deficit hyperactivity disorder in substance use disorder patients: a meta-analysis and meta-regression analysis. Drug Alcohol Depend. 2012;122(1-2):11-19.

7. van de Glind G, Konstenius M, Koeter MW, et al. Variability in the prevalence of adult ADHD in treatment seeking substance use disorder patients: results from an international multi-center study exploring DSM-IV and DSM-5 criteria. Drug Alcohol Depend. 2014;134: 158-166.

8. Huntley Z, Maltezos S, Williams C, et al. Rates of undiagnosed attention deficit hyperactivity disorder in London drug and alcohol detoxification units. BMC Psychiatry. 2012;12:223.

9. Dick DM, Smith G, Olausson P, et al. Understanding the construct of impulsivity and its relationship to alcohol use disorders. Addict Biol. 2010;15(2):217-226.

10. Verdejo-García A, Lawrence AJ, Clark L. Impulsivity as a vulnerability marker for substance-use disorders: review of findings from high-risk research, problem gamblers and genetic association studies. Neurosci Biobehav Rev. 2008;32(4):777-810.

11. Iacono WG, Malone SM, McGue M. Behavioral disinhibition and the development of early-onset addiction: common and specific influences. Annu Rev Clin Psychol. 2008;4:325-348.

12. Willcutt EG, Pennington BF, Chhabildas NA, Friedman MC, Alexander J. Psychiatric comorbidity associated with DSM-IV ADHD in a nonreferred sample of twins. J Am Acad Child Adolesc Psychiatry. 1999; 38(11):1355-1362.

13. Meinzer MC, Lewinsohn PM, Pettit JW, et al. Attention-deficit/ hyperactivity disorder in adolescence predicts onset of major depressive disorder through early adulthood. Depress Anxiety. 2013;30(6):546-553.

14. Taylor MR, Boden JM, Rucklidge JJ. The relationship between ADHD symptomatology and self-harm, suicidal ideation, and suicidal behaviours in adults: a pilot study. Atten Deficit Hyperact Disord. 2014;6(4): 303-312.

15. Baker L, Prevatt F, Proctor B. Drug and alcohol use in college students with and without ADHD. J Atten Disord. 2012;16(3):255-263.

16. Barkley R, Murphy K, Fischer M. ADHD in Adults: What the Science Says. New York: Guilford Press; 2008.

17. Beck AT, Ward CH, Mendelson M, Mock J, Erbaugh J. An inventory for measuring depression. Arch Gen Psychiatry. 1961;4:561-571.

18. Hisli N. Beck Depresyon Envanterinin üniversite öğrencileri için geçerliği, güvenirliği. [Reliability and validity of Beck Depression Inventory among university students]. Turkish Journal of Psychology. 1989;7:3-13. Turkish.

19. Patton JH, Stanford MS, Barratt ES. Factor structure of the Barratt impulsiveness scale. J Clin Psychol. 1995;51(6):768-774.

20. Gulec H, Tamam L, Yazici Gulec M, et al. Psychometric properties of the Turkish version of the Barratt Impulsiveness Scale-11. Bulletin of Clinical Psychopharmacology. 2008;18(4):251-258.

21. Spinella M. Normative data and a short form of the Barratt Impulsiveness Scale. Int J Neurosci. 2007;117(3):359-368.

22. Tamam L, Gulec H, Karatas G. Barratt Dürtüsellik Ölçeği Kısa Formu (BIS-11-KF) Türkçe Uyarlama Çalışması. [Short form of Barratt Impulsiveness Scale (BIS-11-SF) Turkish Adaptation Study]. Arch Neuropsychiatr. 2013;50:130-134. Turkish.
23. Gibbs LE. Validity and reliability of the Michigan alcoholism screening test: a review. Drug Alcohol Depend. 1983;12(3):279-285.

24. Coskunol H, Bagdiken I, Sorias S, Saygili R. Michigan Alkolizm Tarama Testinin Geçerliliği. [Validity and reliability of the Michigan Alcoholism Screening Test (Turkish version)]. Ege Tip Dergisi. 1995;34: 15-18. Turkish.

25. Kessler RC, Adler L, Ames M, et al. The World Health Organization Adult ADHD Self-Report Scale (ASRS): a short screening scale for use in the general population. Psychol Med. 2005;3(2):245-256.

26. Kessler RC, Adler LA, Gruber MJ, Sarawate CA, Spencer T, Van Brunt DL. Validity of the World Health Organization Adult ADHD Self-Report Scale (ASRS) Screener in a representative sample of health plan members. Int J Methods Psychiatr Res. 2007;16(2):52-65.

27. Dogan S, Oncu B, Saracoglu G, Kucukgoncu S. Erişkin Dikkat Eksikliği Hiperaktivite Bozukluğu Kendi Bildirim Ölçeği (ASRS-v1.1): Türkçe formunun geçerlilik ve güvenilirliği [Validity and reliability of the Turkish version of the Adult ADHD Self-Report Scale (ASRS-v1.1)]. Anatolian Journal of Psychiatry. 2009;10(2):77-87. Turkish.

28. Evren C, Umut G, Teksin-Unal G, Agachanli R, Evren B. Psychometric properties of the Turkish version of the Adult ADHD Self-Report Scale (ASRS) in a sample of inpatients with alcohol use disorder. Dusunen Adam. In press 2016.

29. Ameringer KJ, Leventhal AM. Associations between attention deficit hyperactivity disorder symptom domains and DSM-IV lifetime substance dependence. Am J Addict. 2013;22(1):23-32.

30. De Alwis D, Lynskey MT, Reiersen AM, Agrawal A. Attention-deficit/ hyperactivity disorder subtypes and substance use and use disorders in NESARC. Addict Behav. 2014;39(8):1278-1285.

31. de Wit H. Impulsivity as a determinant and consequence of drug use: a review of underlying processes. Addict Biol. 2009;14(1):22-31.

32. Fernández-Serrano MJ, Pérez-García M, Verdejo-García A. What are the specific vs. generalized effects of drugs of abuse on neuropsychological performance? Neurosci Biobehav Rev. 2011;35(3):377-406.

33. Weafer J, Fillmore MT, Milich R. Increased sensitivity to the disinhibiting effects of alcohol in adults with ADHD. Exp Clin Psychopharmacol. 2009; 17(2):113-121.

34. Bramham J, Murphy DG, Xenitidis K, Asherson P, Hopkin G, Young S. Adults with attention deficit hyperactivity disorder: an investigation of age-related differences in behavioural symptoms, neuropsychological function and co-morbidity. Psychol Med. 2012;42(10):2225-2234.

35. WillcuttEG. The prevalence of DSM-IV attention-deficit/hyperactivity disorder: a meta-analytic review. Neurotherapeutics. 2012;9(3):490-499.

36. Bidwell LC, Henry EA, Willcutt EG, Kinnear MK, Ito TA. Childhood and current ADHD symptom dimensions are associated with more severe cannabis outcomes in college students. Drug Alcohol Depend. 2014; 135:88-94.

37. Evren C, Dalbudak E, Evren B, Can Y, Umut G. The severity of attention deficit hyperactivity symptoms and its relationship with lifetime substance use and psychological variables among 10th grade students in Istanbul. Compr Psychiatry. 2014;55(7):1665-1670.

38. Foulds JA, Adamson SJ, Boden JM, Williman JA, Mulder RT. Depression in patients with alcohol use disorders: Systematic review and meta-analysis of outcomes for independent and substance-induced disorders. J Affect Disord. 2015;185:47-59.

39. Evren C, Evren B, Dalbudak E. Alexithymia and personality dimensions in relation to depression and anxiety in male alcohol-dependent inpatients. Int J Psychiatry Clin Pract. 2009;13(1):3-10.

40. Hirvikoski T, Lindholm T, Nordenström A, Nordström A-L, Lajic S. High self-perceived stress and many stressors, but normal diurnal cortisol rhythm, in adults with ADHD (attention-deficit/hyperactivity disorder). Horm Behav. 2009;55(3):418-424. 
Neuropsychiatric Disease and Treatment

Dovepress

\section{Publish your work in this journal}

Neuropsychiatric Disease and Treatment is an international, peerreviewed journal of clinical therapeutics and pharmacology focusing on concise rapid reporting of clinical or pre-clinical studies on a range of neuropsychiatric and neurological disorders. This journal is indexed on PubMed Central, the 'PsycINFO' database and CAS,

and is the official journal of The International Neuropsychiatric Association (INA). The manuscript management system is completely online and includes a very quick and fair peer-review system, which is all easy to use. Visit http://www.dovepress.com/testimonials.php to read real quotes from published authors.

Submit your manuscript here: http://www.dovepress.com/neuropsychiatric-disease-and-treatment-journal 